\title{
Implementation of Step 7 of the Baby-Friendly Hospital Initiative (BFHI) in Finland: Rooming-in according to mothers and maternity-ward staff
}

\author{
Mervi Hakala ${ }^{1,2}$, Pirjo Kaakinen ${ }^{2}$, Maria Kääriäinen ${ }^{2,3}$, Risto Bloigu ${ }^{4}$, Leena Hannula ${ }^{5}$, Satu Elo El, $^{2,3}$
}

\begin{abstract}
INTRODUCTION Rooming-in is an evidence-based practice during which postpartum mothers and infants stay together. Rooming-in benefits both the mother and infant, and is especially important for breastfeeding. This study aims to describe rooming-in (Step 7 of the BFHI), according to mothers and maternity-ward staff in Finnish maternity hospitals, as well as the factors associated with its implementation.

METHODS The presented research adopted a cross-sectional study approach. Questionnaires were used to collect data from mothers $(n=111)$ who had given birth and the attending maternity-ward staff ( $f=1554$ reported events) at 8 Finnish maternity hospitals. The data were analysed using descriptive statistics, as well as chi-squared, t-test, and Fisher, MannWhitney, Kruskal-Wallis tests. Answers to the open-ended questions were analysed using content specifications.

RESULTS Rooming-in was utilised to a satisfactory extent, especially after vaginal birth. Most of the mothers regarded it as a very positive experience. Rooming-in was delayed mainly because of a mother's tiredness and the infant's condition. Factors such as a staff member's age, work experience, and completion of breastfeeding counselling training (WHO 2O-h), a mother's parity, need for supplementation, and mode of childbirth, were found to be associated with the decision to implement rooming-in.

CONCLUSIONS Rooming-in should be used more with infants born by caesarean section and primiparous mothers. The need for supplementation clearly increased when roomingin was not employed. The presented information could be crucial for effectively allocating maternity ward resources and demonstrating the importance of rooming-in to a diverse audience of health care professionals.
\end{abstract}

\author{
AFFILIATION \\ 1 Northern Ostrobothnia Hospital \\ District, Oulaskangas Hospital, \\ Oulainen, Finland \\ 2 Research Unit of Nursing \\ Science and Health Management, \\ University of Oulu, Oulu, Finland \\ 3 Medical Research Center (MRC), \\ Oulu University Hospital and \\ University of Oulu, Oulu, Finland \\ 4 Medical Informatics and \\ Statistics Research Group, \\ University of Oulu, Oulu, Finland \\ 5 Metropolia University of Applied \\ Sciences, Helsinki, Finland
}

\section{CORRESPONDENGE TO}

Mervi Hakala. Northern

Ostrobothnia Hospital District,

Oulaskangas Hospital, Oulainen,

Vanhatie 51, 86220 Merijärvi,

Finland. Email: mervi.hakala@

student.oulu.fi

\section{KEYWORDS}

breastfeeding, postpartum, quantitative research, roomingin, Baby-Friendly Hospital Initiative, Step 7

Received: 24 April 2018

Revised: 14 July 2018

Accepted: 26 July 2018

\section{INTRODUCTION}

The Baby-Friendly Hospital Initiative (BFHI) is meant to support, protect, and promote breastfeeding in facilities providing maternity and infant services ${ }^{1}$. This initiative is a global programme that was launched in 1991 by the World Health Organization (WHO) and UNICEF as a response to an alarming decrease in breastfeeding, and was last revised April 2018. The programme aims to provide new mothers with high-quality clinical care, as well as increase the proportion of mothers who exclusively breastfeed. A practical guideline, termed the 'Ten Steps to Successful Breastfeeding', exists for the successful implementation of BFHI in maternity wards ${ }^{1}$.

Numerous studies have shown that compliance to the $\mathrm{BFHI}$ programme is related to positive outcomes, including breastfeeding ${ }^{2-4}$. Although mothers now spend less time at 
the hospital than before, the BFHI includes a period that is crucial for continued, successful breastfeeding. During their time at the hospital, mothers receive the support they will need to continue breastfeeding at home. The counselling and support that health care professionals provide during the first days is pivotal to ensuring that mothers will continue to exclusively breastfeed at home ${ }^{3,5}$. Baby-Friendly certified hospitals provide maternity ward staff with clear instructions on how they can support breastfeeding. As a result, the maternity-ward staff at these hospitals may work differently than maternity-ward staff in non-Baby-Friendly certified hospitals ${ }^{1}$. In this article, a non-Baby-Friendly certified hospital refers to any hospital that does not have a Baby-Friendly hospital certificate. Global statistics show that in 2017 only 10\% of infants were born in Baby-Friendly certified hospitals. Only a few hospitals (16\%) in Finland are Baby-Friendly certified ${ }^{6}$, but the BFHI Steps are used as general guidelines in every maternity hospital ${ }^{7,8}$.

The proportion of Finnish mothers who exclusively breastfeed has decreased to alarmingly low levels, with only $1 \%$ exclusively breastfeeding at six months in 2012 (National Institute for Health and Welfare $)^{9}$. This falls short of the global average, which now stands at $43 \%$ and has been increasing ${ }^{10}$, and lower than the averages of other Nordic countries (Sweden 14\%, Norway 7\%, Denmark 17\%, Iceland 13\%). Thus, it is important to understand the current rooming-in situation in Finland, as this knowledge is crucial to promoting exclusive breastfeeding. Rooming-in is an evidence-based practice that is used in hospitals to take care of postpartum mothers and their infants during the postpartum period ${ }^{11}$. Rooming-in means that the postpartum mother and her infant are together in the same room after birth for 24 hours a day ${ }^{12,13}$ and they are cared for as a 'couple'14. Roomingin is divided into full rooming-in (24 h), which means that the infant stays in the mother's room day and night, and partial rooming-in, during which the infant is in its mother's room during the day but transferred to the nursery at night ${ }^{15}$. The practice of rooming-in is also Step 7 in the BFHI's 'Ten Steps to Successful Breastfeeding' guideline, which recommends: 'Enable mothers and their infants to remain together and to practise rooming-in throughout the day and night' ${ }^{1}$. In this study, rooming-in refers to full rooming-in. Rooming-in is especially important for breastfeeding. It has been shown to improve breastfeeding in general ${ }^{16}$, exclusive breastfeeding at the hospital ${ }^{17}$, following discharge ${ }^{15,18}$ and exclusive breastfeeding at 6 months $^{19}$, as well as the duration of breastfeeding ${ }^{13}$. Rooming-in makes breastfeeding easier for mothers ${ }^{20}$ as it allows frequent day and night feedings ${ }^{16,21}$. Furthermore, infants who stay in the nursery may be more likely to get fed with formula milk than rooming-in infants ${ }^{22}$. Mother-infant proximity and interactions during early postpartum period are important for breastfeeding success and milk production ${ }^{23}$ and these interactions demand mother and infant stay together. Mothers who room-in have shown a positive attitude towards breastfeeding ${ }^{24}$, and were generally satisfied with the rooming-in experience ${ }^{14}$.

Rooming-in is also important for developing a mother's ability to respond to her infant's needs ${ }^{21}$ and it facilitates a good start to mother-infant interaction ${ }^{25-27}$. It helps mothers learn and recognise their infant's hunger cues ${ }^{28,29}$, and mothers gain self-confidence when they can recognise that their infant is comfortable and contented ${ }^{21,30}$. It also facilitates early bonding and helps mother and infant 'get to know' each other sooner ${ }^{20,31}$. In addition, rooming-in allows a mother to practice both caring for her infant and breastfeeding in a safe environment ${ }^{32}$. The staff can support and counsel parents at all times ${ }^{14}$, and ensure that parents grasp the importance of keeping their infant close $e^{28,33}$. There is evidence that a mother's oxytocin ${ }^{34}$ and beta-endorphin levels ${ }^{24}$ as well as emotional and physical wellbeing increase during rooming-in ${ }^{35}$, and that it helps women embrace their new role of being a mother ${ }^{29,36}$. Furthermore, it was shown that mothers who room-in are more sensitive towards their infant and respond to its needs lovingly and tenderly ${ }^{13,20}$. Mothers and infants who room-in sleep better and experience less anxiety ${ }^{37,38}$. Moreover, skin-to-skin contact, which is easy to use in rooming-in, has been shown to reduce postpartum depressive feelings and maternal physiological stress ${ }^{29}$. Rooming-in increases closeness and bonding between parents and infant ${ }^{17,29}$, strengthens a mother's positive attachment to her infant ${ }^{26}$, reduces depressive feelings and maternal physiological stress ${ }^{29}$ and provides the infant with emotional security ${ }^{33,36}$.

Rooming-in reduces the risk of neonatal complications ${ }^{39}$ such as a diabetic mother's infant hypoglycaemia, morbidity ${ }^{39}$, hyperbilirubinemia ${ }^{16}$ and neonatal abstinence syndrome (NAS), as well as the rate of infant admission to the neonatal intensive care ${ }^{12,40-42}$ and the need for pharmacotherapy ${ }^{41-43}$. Infants cry less ${ }^{44}$ and sleep better ${ }^{22}$ when they are close to their mother. Any separation of a mother and infant disrupts brain development, which is required for bonding. Furthermore, stress hormone levels increase when the infant is away from its mother, possibly destabilising the infant. Preterm infants gain more weight per day when rooming-in ${ }^{45}$, and infants, who have NAS, have shorter stays in the Neonatal Intensive Care Unit (NICU) ${ }^{12,40,41}$, which makes this approach costeffective ${ }^{14,43}$. Rooming-in also benefits nurses, as they are entrusted with higher levels of accountability and can build their competence, which will translate into improvements in staffing flexibility and job satisfaction ${ }^{14}$.

Nevertheless, the negative sides of rooming-in must also be considered. Previous studies have shown that roomingin can interfere with a mother's need to sleep ${ }^{38,46}$. Mothers who room-in may suffer from fatigue, sleep deprivation and exhaustion, and this is common when a mother is responsible for caring for an unsettled infant during the night ${ }^{47}$. Among mothers who room-in, those who gave birth through a caesarean section reported more postpartum fatigue than mothers who gave birth vaginally. Mothers who experience postpartum fatigue have difficulty performing infant-care activities, which can weaken mother-infant attachment ${ }^{38,48}$. According to Hunter et al. ${ }^{38}$, mothers who cannot determine why their infant is crying or who are unfamiliar with babysoothing skills may experience difficulties in infant care. Rooming-in also presents some risks for infants, as 58\% of infant falls happen between midnight and 7 a.m., and 55\% 
of falls occur after a family member falls asleep in a bed or chair ${ }^{17,35}$.

This study aims to describe rooming-in (Step 7 of the $\mathrm{BFHI}$ ) according to mothers and maternity-ward staff in Finnish maternity hospitals and to identify factors associated with the implementation of rooming-in. The study questions were: 'What are postpartum mothers' and maternity ward staff's perceptions of rooming-in?' and 'What background factors are associated with the implementation and duration of rooming-in?'.

\section{METHODS}

\section{Participants and data collection}

Study participants comprised new mothers with their infants and the maternity-ward staff (midwives, childminders/ practical nurses, nurses and students) who cared for the mothers in maternity wards and NICUs in 8 hospitals in Finland. The hospitals were chosen by stratified random sampling, so that the study included two representative hospitals for each of the following types of hospitals defined by the National Institute for Health and Welfare: under 750 deliveries; 750-1500 deliveries; over 1500 deliveries; and university hospital ${ }^{49}$. Two of the eight hospitals had a BFHI certificate. Each maternity hospital had a designated contact person who shared information about the study.

This research employed a cross-sectional study design. Data were collected using two different questionnaires (one for new mothers and the other for maternity-ward staff) during one week in Spring 2014. The research frame is presented in Figure 1 . The study population comprised mothers $(n=509)$ who had given birth during the data collection period and stayed in maternity wards or NICUs, as well as the maternityward staff who attended to these new mothers. Of the new mothers, 279 decided to participate in the study. However, two of the studied hospitals did not allow new mothers to answer the questionnaire. As a result, only 111 new mothers from 6 hospitals answered the questionnaire, representing a response rate of 59\%. The mothers filled in the questionnaire before discharge. An unknown number of maternity-ward staff filled in a total of 1554 questionnaires concerning the 279 mother-infant pairs during the data collection period. The results concerning the maternity-ward staff questionnaire will be presented using the abbreviation $f$. This is because it is possible the same midwife or nurse filled in the questionnaire multiple times. For each mother-infant pair $(n=279)$ included in the study, the maternity-ward staff member who took care of them filled in a questionnaire after every work shift, which means that three questionnaires per mother-infant pair were filled in each day.

\section{Questionnaires}

The questionnaire for mothers as well as the separate questionnaire for maternity-ward staff were developed specifically for this study. The questionnaire for mothers included 31 questions, with 7 background questions and 3 questions about rooming-in. The questionnaire for maternityward staff included 27 questions, of which 9 were background questions and 4 specifically concerned rooming-in. Other

\section{Figure 1. Research frame}

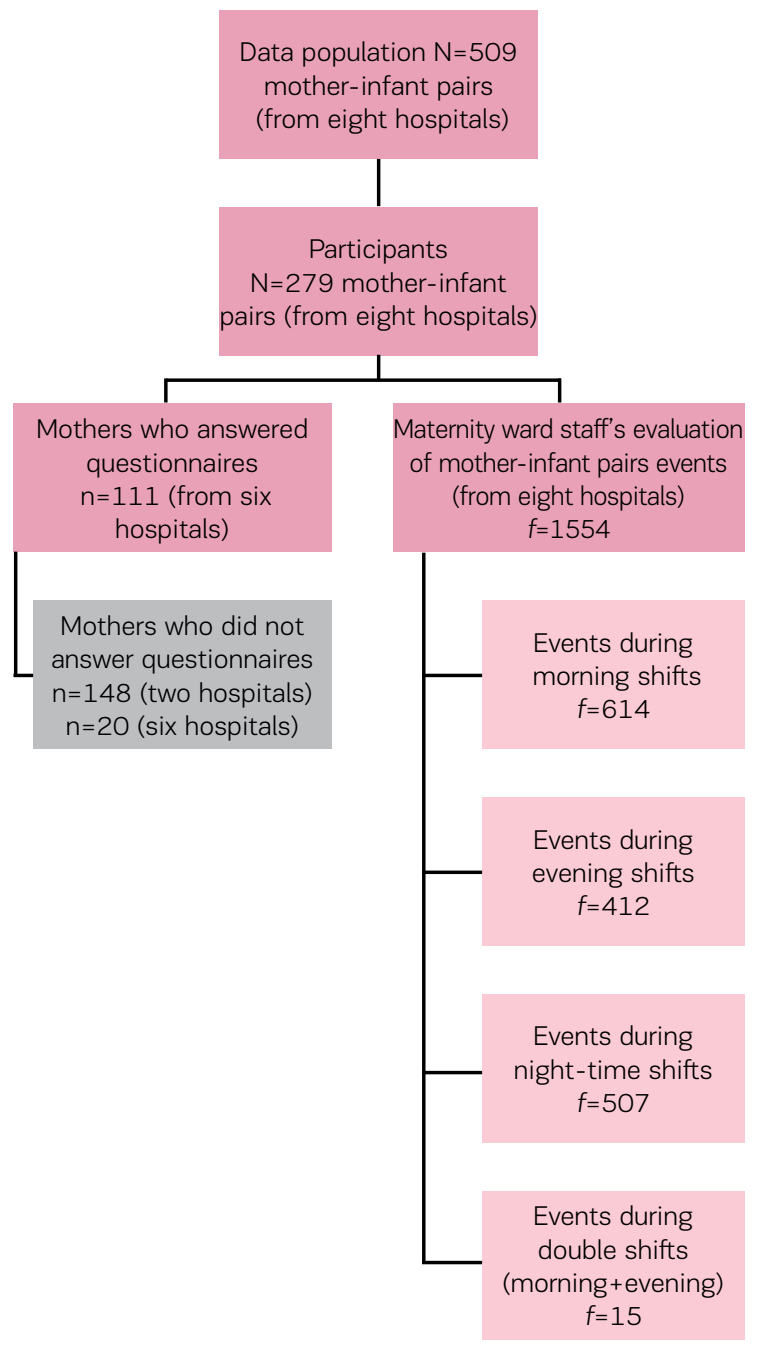

items covered different fields of BFHI, such as skin-to-skin contact, initial breastfeeding and exclusive breastfeeding. The results for BFHI Steps other than rooming-in (Step 7) are reported elsewhere ${ }^{7,8}$. Mothers and maternity-ward staff responded to questions that were multiple choice, graded on a five- or six-point Likert scale, dichotomous (yes/no) or open-ended (Table 1). Data collected from midwives working in the delivery room were used to describe the details of births (Table 2).

The questionnaires included 12 questions from questionnaires that had been used earlier ${ }^{50,51}$, as well as questions created by expert panels. The content validity of the questionnaires was evaluated by three different expert panels: committee members from the Federation of Finnish Midwives $(n=7)$ (content experts, superiors, midwives); midwives $(n=6)$; and experts in instrument development for nursing sciences $(n=3)$ (professor, university lecturer, consultant). A few changes were made to the questionnaires after the evaluation. After an evaluation by the expert panels, the pilot questionnaire was distributed in three maternity 


\section{Table 1. Content and type of questions in mothers' and maternity ward staffs' questionnaires}

\begin{tabular}{|c|c|c|}
\hline Type of question & Mothers' research topics & Maternity ward staff's research topics \\
\hline Open-ended & $\begin{array}{l}\text { age, parity, infant's birthweight, barriers to full } \\
\text { rooming-in, success of breastfeeding, amount } \\
\text { of supplementation during hospitalization, } \\
\text { reasons that blood tests were taken from infants, } \\
\text { hospitalization days }\end{array}$ & $\begin{array}{l}\text { hospital (name, size of hospital, Baby-Friendly } \\
\text { hospital or non-Baby-Friendly hospital), age, } \\
\text { years of work experience, staff's responsibility } \\
\text { during shift, reasons for using skin-to-skin } \\
\text { contact, barriers to full rooming-in, amount of } \\
\text { supplementation, times of blood test, bed-day, } \\
\text { reasons for supplementation, reasons for taking } \\
\text { blood test (infant) }\end{array}$ \\
\hline Multiple-choice & $\begin{array}{l}\text { mode of childbirth, pain relief, starting time of } \\
\text { initial breastfeeding, size of room at ward, quality of } \\
\text { supplementation }\end{array}$ & $\begin{array}{l}\text { occupation, work shift, duration that full rooming-in } \\
\text { was not used, quality of supplementation, method } \\
\text { of supplementation }\end{array}$ \\
\hline $\begin{array}{l}\text { Likert scale } \\
\text { (five-point) }\end{array}$ & $\begin{array}{l}\text { experience of childbirth, success of initial } \\
\text { breastfeeding }\end{array}$ & \\
\hline Likert scale (six-point) & $\begin{array}{l}\text { experience of skin-to-skin contact, experience } \\
\text { of initial breastfeeding, experience of rooming- } \\
\text { in, experience of breastfeeding, experience of } \\
\text { supplementation }\end{array}$ & \\
\hline Dichotomous & $\begin{array}{l}\text { implementation of skin-to-skin contact, need for } \\
\text { initial breastfeeding counselling, adequacy of initial } \\
\text { breastfeeding counselling, continuity of initial } \\
\text { breastfeeding, implementation of full rooming- } \\
\text { in, need for nipple shield, need for pacifier, need } \\
\text { for supplementation, need for blood test (infant), } \\
\text { adequacy of breastfeeding counselling }\end{array}$ & $\begin{array}{l}\text { completion of WHO 2O-h breastfeeding counselling } \\
\text { training, enough knowledge of breastfeeding } \\
\text { counselling, opinion of full rooming-in, } \\
\text { implementation of full rooming-in, adequate time } \\
\text { to provide breastfeeding counselling, success of } \\
\text { breastfeeding, need for breastfeeding counselling, } \\
\text { need for nipple shield, need for supplementation, } \\
\text { need for blood test (infant), implementation of } \\
\text { skin-to-skin contact }\end{array}$ \\
\hline
\end{tabular}

\section{Table 2. Background information for childbirths $(\mathrm{N}=279)$ according to midwives in labour room}

\begin{tabular}{|llll|}
\hline Background & $\boldsymbol{n}$ & $\%$ & range \\
\hline Mothers' parity & & & $1-16$ \\
\hline I-parturient & 125 & 46 & \\
\hline II-parturient & 96 & 35.3 & \\
\hline III-parturient & 28 & 10.3 & \\
\hline IV-parturient & 12 & 4.4 & \\
\hline V-parturient or more & 11 & 4 & \\
\hline Mode of childbirth & & & \\
\hline normal/assisted vaginal & 232 & 86 & \\
\hline caesarean section & 38 & 14 & \\
\hline $\begin{array}{l}\text { Pregnancy weeks at the } \\
\text { time of birth }\end{array}$ & & & \\
\hline 36 or less & 14 & $50-42$ \\
\hline 37-38 & 55 & 20.3 & \\
\hline 39-40 & 143 & 52.7 & \\
\hline 41-42 & 59 & 21.8 & \\
\hline
\end{tabular}

wards. Based on the results, some changes were made, for example, two questions were taken out and some questions were clarified in the maternity-ward staff questionnaire. Four of the questions in the questionnaire for mothers were clarified following the pilot experiment. The questionnaires were formulated in both Finnish and Swedish, which are official languages in Finland. According to the evaluations, the questionnaire for maternity-ward staff was easy to fill in, while performing other hospital duties.

\section{Ethical issues}

Permission to perform the study was requested and received from all the hospitals that participated in the study. Approval was also sought from the Regional Ethics Committee of the Northern Ostrobothnia Hospital District and Turku Clinical Research Centre, yet both unambiguously reported that the study does not require the approval of the Research Ethics Committees based on the Medical Research Act (1999/488). They stated that it was sufficient to receive permission from each participating hospital ${ }^{52}$. One hospital district did not give permission for the mothers to be included in the study but allowed maternity-ward staff to participate.

The low response rate of postpartum mothers could be explained by a mother's condition after giving birth and the strong desire to concentrate on caring for her infant. Participation in the study was voluntary. Maternity-ward staff were informed about the study by a contact person both orally and via a cover letter. Mothers were informed about the study by midwives both orally and via a cover letter. All of the participating maternity-ward staff and mothers gave their informed oral consent based on the provided information. The main researcher did not establish a person register, and the study ensured the anonymity of every participant ${ }^{53}$. The questionnaires and the data they produced were coded in such a way that the researchers could handle the data without losing information about which mother-infant pair was described. 


\section{Data analysis}

The data were analysed using SPSS Statistics for Windows (version 24.0, IBM, Armonk, NY) ${ }^{54}$. The data were first examined using descriptive statistics (frequencies, percentages). Differences between background variables and main (rooming-in) variables were tested using chi-squared, t-test, and Fisher, Mann-Whitney, Kruskal-Wallis tests. All of the results presented in this study are statistically significant $(p<0.05)^{53}$. Open-ended questions were analysed based on content specifications ${ }^{55,56}$. Answers to open questions were typically short, consisting of only a couple words or short paragraphs. Therefore, it was not possible to perform a deep content analysis. Content specification was adopted as qualitative answers describe phenomena better than quantitative answers ${ }^{57}$. Content was organized into two categories - category and subcategory. Participants with missing data were excluded. Results regarding new mothers are described using the number of observations (n), while nursing events are described using the amount of reported effects $(f)$ in the questionnaires filled in by maternity-ward staff after each work shift. Results of open-ended questions are presented using $q$, which describes the number of times a certain word, phrase or concept appeared in the open-ended questions.

\section{RESULTS}

\section{Characteristics of participants}

The mean age of mothers $(n=111)$ was 30 years (range 1946 years). Of the mothers that answered the questionnaire, $82 \%(n=91)$ gave normal birth vaginally, $9 \%(n=10)$ vacuumassisted vaginally, $1.8 \%(n=2)$ breech birth vaginally and $7.2 \%(n=8)$ by caesarean section. About a third $(31 \%, n=34)$ of the mothers were primiparous. One set of twins was included in the data. Mothers stayed at the maternity-ward in either single rooms $(n=13,12 \%)$, double rooms $(n=46$, $42 \%)$, a family room $(n=5,4 \%)$, or rooms with three, four or six beds ( $n=46,42 \%)$. The average hospital stay lasted 2.6 days (range $1-8$ days).

The characteristics of the maternity-ward staff are presented in Table 3. The average staff member participating in this study was 43 years old and had 16 years of work experience. Most of the questionnaires were filled in by midwifes ( $n=961,67 \%$ ), and almost all of the respondents (97\%) had completed breastfeeding counselling training (WHO 20-h). The maternity-ward staff were responsible for an average of 4.5 infants per shift (range 0-29). According to the maternity-ward staff, the average length of a mother's pregnancy was 39 weeks (range 30-42 weeks), with the average infant weight at $3500 \mathrm{~g}$ (range 1890-4660 g). Furthermore, the maternity-ward staff reported that $86 \%$ $(n=232)$ of the mothers included in the study gave birth vaginally and $46 \%(n=125)$ of them were primiparous (Table 2). These results can be compared with the responses of mothers presented above.

Mothers' evaluation of rooming-in and factors related to its implementation

Most mothers ( $86 \%, n=94)$ agreed that rooming-in was used
Table 3. Background information for maternity ward staff $(f=1554)$

\begin{tabular}{|llll|}
\hline $\begin{array}{l}\text { Background } \\
\text { Occupation of staff }\end{array}$ & $\boldsymbol{n}$ & $\%$ & range \\
$\begin{array}{l}\text { midwives } \\
\text { children's practical nurses and } \\
\text { practical nurses }\end{array}$ & 961 & 66.7 & \\
$\begin{array}{l}\text { nurses } \\
\text { students }\end{array}$ & 76 & 5 & \\
\hline $\begin{array}{l}\text { Age of maternity ward } \\
\text { staff, years }\end{array}$ & 5 & 0.3 & $20-64$ \\
\hline 20-30 & & & \\
\hline 31-40 & 320 & 21 & \\
\hline $41-50$ & 349 & 23 & \\
\hline 51-60 & 318 & 20 & \\
\hline over 60 & 499 & 32 & \\
\hline Years of work experience & 62 & 4 \\
\hline O-10 & 638 & 43 \\
\hline 11-20 & 272 & 18 \\
\hline 21-30 & 380 & 25 \\
\hline 31-40 & 209 & 14 \\
\hline Shift & & \\
\hline morning & 614 & 40 \\
\hline evening & 412 & 26 \\
\hline night & 507 & 33 \\
\hline double (morning + evening) & 15 & 1 \\
\hline Staff with WHO 20-h & & \\
\hline
\end{tabular}

Staff with WHO 20-h

breastfeeding counselling

training

$\begin{array}{lll}\text { Yes } & 1502 & 97 \\ \text { No } & 52 & 3\end{array}$

Staff's responsibility of infants during shift

0-5 infants/nurse

$1132 \quad 74$

6-10 infants/nurse

$348 \quad 23$

11 or over infants/nurse

50

23

to a suitable extent. The size of the room $(p=0.046)$ was associated with whether or not rooming-in was employed. Rooming-in was always used when the mother stayed in the family room, and in $93 \%$ of cases in which the mother stayed in a room with three to six beds. However, only $74 \%$ of mothers in double rooms roomed-in with their infants. The infants who roomed-in needed less supplementation than the infants in the nursery $(p=0.025)$.

In all, $81 \%$ of mothers experienced rooming-in as positive and most multiparous $(p=0.013)$ mothers reported it to be a highly positive experience. A positive perception of skinto-skin contact after labour was associated $(p=0.001)$ with a positive experience of rooming-in.

Maternity-ward staff's evaluation of rooming-in and factors associated with its implementation

The maternity-ward staff $(f=1447)$ reported that rooming-in was used following $91 \%$ of births. The staff member's age 
$(p=0.049)$, work experience $(p=0.022)$, and completion of breastfeeding counselling training (WHO 20-h) $(p=0.001)$ were associated with a mother's decision to room-in with her infant (Table 4). Staff members who were over 60 years old and had extensive work experience implemented rooming-in more often than their younger, less experienced counterparts. Maternity-ward staff who had worked for over 30 years suggested that mother-infant pairs should room-in more often than staff with 0-10 years of experience. Furthermore, maternity-ward staff who had completed breastfeeding counselling training (WHO 20-h) were more inclined to apply the rooming-in approach than staff who had not completed this training. The implementation of rooming-in was also associated with staff having adequate time to provide breastfeeding counselling $(p=0.000)$ and the mode of childbirth $(p=0.000)$ (Table 4$)$. When the staff had adequate time to implement breastfeeding counselling, rooming-in was employed in $93 \%$ of the cases. Rooming-in was more commonly used after a vaginal birth than after a caesarean section. Rooming-in was more positively perceived when it was used after a vaginal delivery than after a caesarean section $(p=0.026)$. According to maternity ward-staff, there was a strong association between implementation of rooming-in and skin-to-skin contact at the postpartum ward $(p=0.014)$ (Table 4).

A staff member's occupation $(p=0.004)$ was associated with their opinion of rooming-in (Table 4). Midwives and nursing students were more satisfied with rooming-in than children's-practical-nurses/practical-nurses and nurses. The decision to implement rooming-in $(p=0.021)$ and mode of childbirth $(p=0.026)$ were also associated with a staff member's opinion of full rooming-in (Table 4).

\section{The duration of rooming-in along with relevant factors}

The maternity-ward staff took care of the infants for an average of 2.3 hours per shift. Most of the infants were with maternity-ward staff for either under one hour $(36 \%, f=64)$ or for over five hours ( $26 \%, f=45)$. Work shift $(p=0.002)$, work load $(p=0.006)$ and the mode of child birth $(p=0.009)$ were all associated with the duration of rooming-in (Table 4). Nurses working double or night shifts reported longer durations during which infants were away from their mothers than nurses working other shifts. Infants were away from their mothers for over five hours in 50\% and 35\% of cases when maternity-ward staff were working double and night shifts, respectively. The infant was with its mother for a longer period of time when maternity-ward staff members had enough time during their shift to provide breastfeeding counselling than when either only partial counselling was implemented, or the infant was born by caesarean section.

Infants at university hospitals were more often out of the room for over five hours than infants at hospitals with 750-1500 deliveries, and this difference was statistically significant $(p=0.006)$. Furthermore, infants at Baby-Friendly certified hospitals were more often out of the room for over one hour than infants at non-Baby-Friendly certified hospitals $(p=0.005)$. Primiparous mothers' infants were out of the room for three hours more often than the infants of multiparous mothers $(p=0.027)$. The duration of rooming-in was found to be associated with implementation of roomingin $(p=0.000)$ (Table 4).

\section{Barriers to rooming-in according to mothers and maternity-ward staff}

Barriers to rooming-in were identified from answers to open-ended questions, and both mothers $(n=17)$ and maternity-ward staff $(f=137)$ described multiple reasons for why rooming-in was unsuccessful. Most of the barriers $(q=73)$ were related to a mother's postpartum condition, namely, fatigue, need to rest and sleep $(q=24)$, basic needs $(q=25)$ (e.g. shower) and consequences of caesarean section

\section{Table 4. Relationship between maternity ward staff background variables and the implementation, duration} and professional opinion of rooming-in

\begin{tabular}{|c|c|c|c|}
\hline & Implementation of rooming-in & Duration of rooming-in & Opinion of full rooming-in \\
\hline Age & $p=0.049$ & $n s^{*}$ & $\mathrm{~ns}^{*}$ \\
\hline Occupation & $\mathrm{ns}^{*}$ & $\mathrm{~ns}^{*}$ & $p=0.004$ \\
\hline Years working as a nurse & $p=0.022$ & $n s^{*}$ & $\mathrm{~ns}^{*}$ \\
\hline Work shift & $\mathrm{ns}^{*}$ & $p=0.002$ & $n s^{*}$ \\
\hline $\begin{array}{l}\text { Breastfeeding counselling training } \\
\text { (WHO } 20 \mathrm{~h} \text { ) }\end{array}$ & $p=0.001$ & $n s^{*}$ & $\mathrm{~ns}^{*}$ \\
\hline $\begin{array}{l}\text { Implementation of skin-to-skin } \\
\text { contact }\end{array}$ & $p=0.014$ & $\mathrm{~ns}^{*}$ & $\mathrm{~ns}^{*}$ \\
\hline Implementation of rooming-in & $x$ & $p=0.000$ & $p=0.021$ \\
\hline $\begin{array}{l}\text { Adequate time to provide } \\
\text { breastfeeding counselling }\end{array}$ & $p=0.000$ & $p=0.006$ & $n s^{*}$ \\
\hline Size of hospital & $\mathrm{ns}^{*}$ & $p=0.006$ & $\mathrm{~ns}^{*}$ \\
\hline Mother's parity & $\mathrm{ns}^{*}$ & $p=0.027$ & $\mathrm{~ns}^{*}$ \\
\hline Baby Friendly certification & $\mathrm{ns}^{*}$ & $p=0.005$ & $\mathrm{~ns}^{*}$ \\
\hline Mode of childbirth & $p=0.000$ & $p=0.009$ & $p=0.026$ \\
\hline
\end{tabular}


Table 5. Barriers to rooming-in according to mothers and maternity ward staff

\begin{tabular}{|c|c|c|c|c|c|}
\hline Mothers & $q$ & $\%$ & Maternity ward staff & $q$ & $\%$ \\
\hline $\begin{array}{l}\text { Mother's need to } \\
\text { rest and sleep, } \\
\text { fatigue }\end{array}$ & 8 & 40 & $\begin{array}{l}\text { Mother's need to rest } \\
\text { and sleep, fatigue }\end{array}$ & 31 & 18.7 \\
\hline $\begin{array}{l}\text { Infant care in } \\
\text { NICU }\end{array}$ & 6 & 30 & Infant care in NICU & 33 & 19.9 \\
\hline $\begin{array}{l}\text { Caesarean } \\
\text { section }\end{array}$ & 2 & 10 & Caesarean section & 11 & 6.6 \\
\hline Restless infant & 2 & 10 & Restless infant & 11 & 6.6 \\
\hline $\begin{array}{l}\text { Insufficiency of } \\
\text { breast milk }\end{array}$ & 1 & 5 & $\begin{array}{l}\text { Infant spends a long } \\
\text { time at breast }\end{array}$ & 2 & 1.2 \\
\hline \multirow{5}{*}{$\begin{array}{l}\text { Infant's light } \\
\text { therapy }\end{array}$} & 1 & 5 & Infant's light therapy & 11 & 6.6 \\
\hline & & & Mother's basic needs & 25 & 15 \\
\hline & & & Mother's problems & 22 & 13.2 \\
\hline & & & Mother out of the ward & 10 & 6 \\
\hline & & & Infant's treatment & 10 & 6 \\
\hline
\end{tabular}

$(q=11)$ (e.g. pain), with the two most common barriers being a mother's fatigue, need to rest and sleep, and infant admittance to the NICU (Table 5). All of the reported barriers to rooming-in are detailed in Table 5.

\section{DIScussion}

When the results from the mothers and maternity-ward staff included in this study are considered together, it can be stated that rooming-in was implemented to a satisfactory extent, which is comparable to an earlier study concerning Southern Finland ${ }^{30}$.

Early skin-to-skin contact and initial breastfeeding after labour were found to be associated with the implementation of rooming-in. This practice enables positive bonding between the infant and mother ${ }^{28}$ and, together with rooming-in, promotes mother-infant interaction ${ }^{58}$ along with sustained, long-term exclusive breastfeeding ${ }^{3,18}$. This study also identified an association between early skin-toskin contact following labour and a positive experience of rooming-in. An infant gets the best start to its life through the many benefits of rooming-in ${ }^{17}$, and all maternity-ward staff should understand and apply this concept in their work. One study has suggested that non-separation benefits fullterm infants and their mothers ${ }^{28}$, as well as maternity-ward staff ${ }^{14}$. The maternity-ward staff unanimously felt that full rooming-in is good hospital practice. One study has found that full rooming-in increases nurses' job satisfaction and affords them more responsibility ${ }^{14}$. A staff member's occupation was associated with their opinion of roomingin, i.e. all midwives felt that it is good practice but staff representing other occupations did not share unanimously a positive perception. This may be because the education of these other professions does not concentrate on the benefits of breastfeeding and keeping the mother and infant together, as much as the curriculum of midwives. An evidence-based review by Jaafar et al. ${ }^{18}$ found limited support for the claim that rooming-in is better than separation after birth in terms of exclusive breastfeeding once the mother is home. The outcomes showed that rooming-in translated to a higher frequency of breastfeeding and improved rates of exclusive breastfeeding four days postpartum. Nevertheless, the research included a brief study period and acknowledged that further information about the realised benefits of rooming-in are need, which the presented study doesn't provide.

The age and work experience of maternity-ward staff were both associated with the decision to implement roomingin. Extensive work experience underlies taking good care of mother-infant couples. Breastfeeding counselling training (20-h) seems to be a good form of education for maternityward staff as it was found to be associated with how often rooming-in is utilised. However, this education should be mandatory for all maternity-ward staff rather than just the midwives who attend to mother-infant couples, as roomingin rates were higher when staff members reported having enough time to provide breastfeeding counselling. Insufficient resources for breastfeeding counselling require wards to be well organised and to concentrate on mothers who are at risk of not breastfeeding their infant. The mode of childbirth also affected whether or not rooming-in was implemented. In this study, rooming-in was very common after normal vaginal childbirth, and most health care professionals felt that it is more appropriate after vaginal delivery than following a caesarean section. However, the separation of mother and infant after a caesarean section increases stress hormone levels in infants, and these infants also have lower betaendorphin levels than infants born through vaginal deliveries ${ }^{32}$. Following early separation, a mother's oxytocin and prolactin levels decrease while her epinephrine levels increase, which can lead to increased stress ${ }^{32}$. Mothers who deliver through a caesarean section need more help and support during rooming-in. Maternity-ward staff are competent in providing breastfeeding assistance to mothers who had a caesarean section, especially if they have completed breastfeeding counselling training (WHO 20-h), yet it is sometimes difficult to realise that a mother needs assistance ${ }^{24}$.

When full rooming-in was not used, the infant was out of the mother's room for an average of two hours per shift. Most of the breaks lasted less than one hour and were the result of a mother's basic needs. Infants in the nursery are more likely to receive supplementation than infants who room-in ${ }^{22}$, and this is not beneficial for the frequency of breastfeeding. The results presented in this study agree with previous findings. The most dangerous consequence of an infant receiving supplementation at the hospital is that the mother may feel that she does not have enough breast milk to feed her infant. Infants in the nursery also used a pacifier more than infants who roomed-in, but this finding was not statistically significant. The finding demonstrates that infants' sucking needs are sated by a pacifier. Long-term exclusive breastfeeding requires a large amount of emotional support, self-efficacy and good experiences from the hospital so that mothers continue breastfeeding at home ${ }^{30}$. Roomingin can be essential to a mother learning her infant's hunger cues $^{28}$ and being able to immediately respond to them ${ }^{21}$; it also facilitates frequent feeding ${ }^{16,18}$ and helps mothers to 
'get to know' their infants sooner ${ }^{31}$. As a result, rooming-in increases exclusive breastfeeding ${ }^{16}$, makes breastfeeding easier ${ }^{20}$ and builds a loving and tender relationship between infant and mother ${ }^{28,29,41}$.

The BFHI programme aims to support, promote and protect exclusive breastfeeding in every hospital around the world ${ }^{59}$. One surprising result in this study was that BFHIcertified hospitals did not stand out in terms of rooming-in practice. Infants in BFHI-certified hospitals were out of their rooms more than infants in non-BFHI-certified hospitals. This demonstrates that all Finnish hospitals have a similar stance regarding Step 7 of $\mathrm{BFHI}$ and that our birth and postpartum culture is well-aligned with the BFHI advice. In Finland all hospitals work with postpartum mothers and their infants in a quite similar way, although some of them are BFHI-certified. The culture of interactions during postpartum time are deep rooted in a country. We did, however, find that hospital size affects rooming-in utilisation in Finland, as rooming-in was used significantly more at hospitals with 750-1500 childbirths than at university hospitals. This finding may be explained by smaller hospitals having more single, family and double rooms, which would increase connectivity and thus rooming-in. The size of the room also influenced the implementation of rooming-in, as rooming-in was more common in double rooms than in smaller (single) or bigger (three to six beds) rooms. The lower rates of rooming-in in the largest rooms may have been a result of mothers feeling pressure to allow the other mothers an opportunity to sleep. One important factor to increase rooming-in may be family support for it. Nowadays fathers spend more time at wards and may care infants with mothers and so increase roomingin. Our study did not research this factor.

The results clearly demonstrated that a mother's need to sleep and rest is a main barrier to successful rooming-in, and this problem has been highlighted by another study ${ }^{46}$. Mothers who were primiparous, gave birth by caesarean section ${ }^{38,48}$ and/or had a complicated and prolonged labour were more at risk to postpartum fatigue. Any mother who has undergone a difficult labour or caesarean section requires ample rest so that they can fully recover both physically and psychologically ${ }^{21}$. Hospitals are responsible for ensuring a mother's wellbeing, and partial rooming-in may be a solution for mothers experiencing postpartum fatigue. It is good practice to allow a mother to leave an infant at the nursery for a short time when she is too tired or stressed, and this has been shown to make exclusive breastfeeding less demanding ${ }^{15}$ and to improve a mother's self-efficacy ${ }^{30}$. In this study, infants were out of the room for the longest periods at nights and during double shifts. This demonstrates that the studied hospitals are actively working to prevent mothers' postpartum fatigue. Exclusive breastfeeding is also possible with partial rooming-in. Maternity-ward staff can provide breastfeeding counselling to help mothers understand the importance of exclusively breastfeeding at night and that they can manage even when they are tired. Other studies have presented contradictory results regarding complaints about rooming-in and a mother's fatigue. Some of these studies found that mothers who practice rooming-in sleep better and have less anxiety ${ }^{37,38}$. For this reason, maternityward staff have to be adept at recognising differences among mother-infant couples. In this way, they can help mothers decide whether rooming-in is the best choice for them and their infant. In this study, maternity-ward staff reported not having sufficient time to provide complete breastfeeding counselling, which is a concern. Under time pressure, the maternity-ward staff concentrated on counselling the essential mothers, i.e. primiparous women and mothers who had delivered via caesarean section. A possible reason for this decision is that if these mothers are supported well following the birth of their first child, then they will not need as much support during future deliveries.

Infants' treatment in the nursery or NICU prevents the implementation of rooming-in. This could explain why not all of the mothers included in this study roomed-in with their infants. Based on evidence from previous research, this needs to change in the future. Numerous studies have shown that it is beneficial for mother and infant to be close. For this reason, hospitals should seriously consider adding family rooms to the NICU. The possibility of rooming-in in the NICU could, according to previous literature, have beneficial effects in terms of NAS treatment ${ }^{12,41}$, prevalence of neonatal hypoglycaemia ${ }^{39}$ and infections ${ }^{60}$, as well as length of NICU stay $^{41}$. Postnatal NAS can occur following the discontinuation of drug use by the infant's mother and is a typical problem in infants born to mothers who are dependent on opioids ${ }^{41}$. Many other reasons prevented rooming-in but they occurred less often.

\section{Limitations}

This study focused only on one country and included a limited number of participants. The maternity-ward staff's questionnaires could have been filled in by the same personnel multiple times, therefore having the same results reported, which may influence some of the parameters evaluated in the study. Hence further research is needed with a more targeted population to obtain concrete information on the impact of rooming in Finnish maternity wards.

\section{CONCLUSIONS}

This study has shown that maternity wards in Finnish hospitals implement the practice of rooming-in to a satisfactory extent, as a substantial number of mother-infant couples are together during the postpartum period. This allows mothers and infants to get the best possible start to breastfeeding. Moreover, infants in the nursery received more formula milk than infants who roomed-in. This study supports increased implementation of the BFHI programme across Finnish hospitals, and contributes knowledge pertaining to Step 7 (rooming-in) of the initiative. Roomingin was used to a large extent with multiparous mothers and after vaginal birth. One clear challenge is how maternity-ward staff could increase rooming-in among primiparous women and mothers who delivered via caesarean section. More research is necessary before solutions to this challenge can be postulated. The current situation in Finland is promising, but there are still some problems that need to be addressed. 
Our main recommendation would be that all maternity-ward staff clearly understand the importance of and their role in implementing rooming-in with the end goal being long-term, exclusive breastfeeding. A key part of this is that all staff members have completed the WHO 20-h breastfeeding counselling training, as staff who have completed this education implement rooming-in more often than staff who lack this training.

\section{REFERENGES}

1. WHO \& Unicef. Implementation guidance: Protecting, promoting and supporting breastfeeding in facilities providing maternity and newborn services - the revised Baby-Friendly Hospital Initiative. http://www. who.int/nutrition/publications/infantfeeding/bfhiimplementation-2018.pdf?ua=1. Updated 2018. Accessed April 2018.

2. Pérez-Escamilla R, Martinez JL, Segura-Pérez S. Impact of the Baby-Friendly Hospital Initiative on breastfeeding and child health outcomes: A systematic review. Matern Child Nutr. 2016;12(3):402-417. doi:10.1111/mcn.12294.

3. Perrine CG, Scanlon KS, Li R, Odom E, Grummer-Strawn L. Baby-Friendly hospital practices and meeting exclusive breastfeeding intention. Pediatrics. 2012;130(1):54-60. doi:10.1542/peds.2011-3633.

4. Grguric J, Zakarija-Grkovic I, Pavicic Bošnjak A, Stanojevic M. A multifaceted approach to revitalizing the Baby-Friendly Hospital Initiative in Croatia. J Human Lactation. 2016;32(3):568-573. doi:10.1177/0890334415625872.

5. Hannula L, Kaunonen M, Tarkka M. A systematic review of professional support interventions for breastfeeding. J Clin Nurs. 2008;17(9):1132-1143. doi:10.1111/j.1365-2702.2007.02239.x

6. Bagci Bosi AT, Eriksen KG, Sobko T, Wijnhoven TMA, Breda J. Breastfeeding practices and policies in WHO European Regionmemberstates.PublicHealthNutr.2015;19(4):753764. doi:10.1017/s1368980015001767.

7. Hakala M, Kaakinen P, Kääriäinen M, Bloigu R, Hannula L, Elo $S$. The realization of BFHI step 4 in Finland - initial breastfeeding and skin-to-skin contact according to mothers and midwives. Midwifery. 2017;50:27-35. doi:10.1016/j.midw.2017.03.010

8. Hakala M, Laukkala H, Kaakinen P, Elo S. Vauvamyönteisyyden nykytila Suomessa vastasyntyneen ihokontaktin toteutumisen osalta. (Present state of baby-friendliness in Finland with a focus of part infants skin-to-skin contact. In Finnish with English abstract) Tutkiva hoitotyö. (Nursing Evidence) 2015;13(4):15-24.

9. THL. Imeväisikäisten ruokinta Suomessa vuonna 2010 (Infant feeding in Finland 2010). https://www.thl.fi/ documents/10531/95751/Raportti\%202012\%208. pdf. Updated 2012. Accessed April 2018.

10. UNICEF. Improving breastfeeding, complementary foods and feeding practices. Updated 2017. Accessed April 2018.

11. International Federation of Gynecology and Obstetrics,
International Confederation of Midwives, White Ribbon Alliance, International Pediatric Association, World Health Organization. Mother-Baby Friendly birthing facilities. International Journal of Gynecology \& Obstetrics. 2015;128(2):95-99. doi:10.1016/j.ijgo.2014.10.013.

12. Abrahams RR, MacKay-Dunn MH, Nevmerjitskaia V, MacRae GS, Payne SP, Hodgson ZG. An evaluation of rooming-in among substance-exposed newborns in BritishColumbia.JObstetGynaecolCan.2010;32(9):866871. doi:10.1016/s1701-2163(16)34659-x.

13. Crenshaw JT. Healthy birth practice \#6: Keep mother and baby Together-It's best for mother, baby, and breastfeeding. J PERINAT EDUC. 2014;23(4):211-217. doi: 10.1891/1058-1243.23.4.211.

14. Waller-Wise R. Mother-baby care: The best for patients, nurses and hospitals. Nursing for Women's Health. 2012;16(4):273-278. doi:10.1111/j.1751-486x.2012.01744.x.

15. ZuppaAA,SindicoP,AntichiE, etal.Weightlossandjaundice in healthy term newborns in partial and full rooming-in. J MATERN FETAL NEONAT MED. 2009;22(9):801-805. doi:10.1080/14767050902994499.

16. Chiou S, Chen L, Yeh H, Wu S, Chien L. Early skin-to-skin contact, rooming-in, and breastfeeding: A comparison of the 2004 and 2011 national surveys in Taiwan. Birth. 2014;41(1):33-38. doi:10.1111/birt.12090.

17. Feldman-Winter L, Goldsmith JP, Moon RY, et al. Safe sleep and skin-to-skin care in the neonatal period for healthy term newborns. Pediatrics. 2016;138(3). doi:10.1542/peds.2016-1889.

18. Jaafar SH, Ho JJ, Lee KS. Rooming-in for new mother and infant versus separate care for increasing the duration of breastfeeding. CochraneDatabase Syst Rev.2016;2016(8). doi: 10.1002/14651858.cd006641.pub3.

19. Waits A, Guo C-, Chien L-. Evaluation of factors contributing to the decline in exclusive breastfeeding at 6 months postpartum: The 2011-2016 national surveys in Taiwan. Birth. 2018;45(2):184-192. doi:10.1111/birt.12340.

20. Crenshaw J. Care practice \#6: No separation of mother and baby, with unlimited opportunities for breastfeeding. J PERINAT EDUC. 2007;16(3):39-43.

21. Jaafar SH, Lee KS, Ho JJ. Separate care for new mother and infant versus rooming-in for increasing the duration of breastfeeding. Cochrane Database Syst Rev. 2012(9):N. PAG-N.PAG. doi:10.1002/14651858.cd006641.pub2.

22. Svensson K, Matthiesen A, Widström A. Night roomingin: Who decides? An example of staff influence on mother's attitude. Birth. 2005;32(2):99-106. doi:10.1111/j.0730-7659.2005.00352.x.

23. Bigelow AE, Power M, Gillis DE, Maclellan-Peters J, Alex M, McDonald C. Breastfeeding, skin-to-skin contact, and mother-infant interactions over infants' first three months. Infant Mental Health Journal. 2014;35(1):5162. doi:10.1002/imhj.21424.

24. Lin C, Kuo S, Lin K, Chang T. Evaluating effects of a prenatal breastfeeding education programme on women with caesarean delivery in Taiwan. J Clin Nurs. 2008;17(21):2838-2845. 
doi:10.1111/j.1365-2702.2008.02289.x

25. Moore ER, Anderson GC, Bergman N, Dowswell T. Early skin-to-skin contact for mothers and their healthy newborn infants. Cochrane Database Syst Rev. 2012;5. doi: 10.1002/14651858.cd003519.pub3

26. Serpero LD, Sabatini M, Colivicchi M, Gazzolo D. Roomingin: An update. Early Hum Dev. 2013;89(SUPPL4). doi: 10.1016/s0378-3782(13)70082-3.

27. Bystrova K, Ivanova V, Edhborg M, et al. Early contact versus separation: Effects on mother--infant interaction one year later. Birth. 2009;36(2):97-109. doi:10.1111/j.1523-536x.2009.00307.x

28. Dumas L, Lepage M, Bystrova K, Matthiesen A-, Welles-Nyström B, Widström A-. Influence of skin-to-skin contact and rooming-in on early mother-infant interaction: A randomized controlled trial. Clin Nurs Res. 2013;22(3):310-336. doi:10.1177/1054773812468316.

29. Bigelow A, Power M, MacLellanPeters J, Alex M, McDonald C. Effect of mother/infant skin-to-skin contact on postpartum depressive symptoms and maternal physiological stress. JOGNN - Journal of Obstetric, Gynecologic, \& Neonatal Nursing. 2012;41(3):369-382. doi:10.1111/j.1552-6909.2012.01396_1.x.

30. Koskinen KS, Aho AL, Hannula L, Kaunonen M. Maternity hospital practices and breast feeding self-efficacy in Finnish primiparous and multiparous women during the immediate postpartum period. Midwifery. 2014;30(4):464-470. doi:10.1016/j.midw.2013.05.003

31. Memo L, Longo G, Soriani P. Care procedures for healthy term newborn in maternity ward: The 'open' nursery. Early Hum Dev. 2011;87(SUPPL.). doi:10.1016/j.earlhumdev.2011.01.038.

32. Buckley SJ. Executive summary of hormonal physiology of childbearing: Evidence and implications for women, babies, and maternity care. National partnership for women \& families. Reproduced with permission. J PERINAT EDUC. 2015;24(3):145-153. doi:10.1891/1058-1243.24.3.145.

33. Doorenbos A, Lindhorst T, Starks H, Aisenberg E, Curtis JR, Hays R. Palliative care in the pediatric ICU: Challenges and opportunities for family-centered practice. J SOC WORK END LIFE PALLIAT CARE. 2012;8(4):297-315. doi:10.1080/15524256.2012.732461.

34. Winberg J. Mother and newborn baby: Mutual regulation of physiology and behavior - A selective review. Dev Psychobiol. 2005;47(3):217-229. doi:10.1002/dev.20094.

35. Wallace SC. Preventing newborn falls while supporting family bonding. Am J Nurs. 2015;115(11):58-61. doi:10.1097/01.naj.0000473316.09949.1f.

36. McLachlan HL, Forster DA, Yelland J, Rayner J, Lumley $J$. Is the organisation and structure of hospital postnatal care a barrier to quality care? Findings from a state-wide review in Victoria, Australia. Midwifery. 2008;24(3):358370. doi:10.1016/j.midw.2006.10.006.

37. Bergman JHDE, Bergman N. Whose choice? Advocating birthing practices according to baby's biological needs.
Journal of Perinatal Education. 2013;22(1):8-13. doi:10.1891/1058-1243.22.1.8.

38. Hunter LP, Rychnovsky JD, Yount SM. A selective review of maternal sleep characteristics in the postpartum period. JOGNN. 2009;38(1):60-68. doi:10.1111/j.1552-6909.2008.00309.x.

39. Stage E, Mathiesen ER, Emmersen PB, Greisen G, Damm P. Diabetic mothers and their newborn infants - rooming-in and neonatal morbidity. Acta Paediatr Int J Paediatr. 2010;99(7):997-999. doi:10.1111/j.1651-2227.2010.01779.x.

40. Abrahams RR, Kelly SA, Payne S, Thiessen PN, Mackintosh $J$, Janssen PA. Rooming-in compared with standard care for newborns of mothers using methadone or heroin. Can Fam Phys. 2007;53(10):1722-1730.

41. Newman A, Davies GA, Dow K, et al. Rooming-in care for infants of opioid-dependent mothers: Implementation and evaluation at a tertiary care hospital. Can Fam Physician. 2015;61(12):e555-e561.

42. MacMillan KDL, Rendon CP, Verma K, Riblet N, Washer DB, Volpe Holmes A. Association of rooming-in with outcomes for neonatal abstinence syndrome: A systematic review and meta-analysis. JAMA Pediatr. 2018;172(4):345351. doi:10.1001/jamapediatrics.2017.5195

43. Pritham UA. Breastfeeding promotion for management of neonatalabstinencesyndrome.JOGNN.2013;42(5):517526. doi: 10.1111/1552-6909.12242.

44. Stremler R, Dhukai Z, Wong L, Parshuram C. Factors influencing sleep for parents of critically ill hospitalised children: A qualitative analysis. Intensive Crit Care Nurs. 2011;27(1):37-45. doi: 10.1016/j.iccn.2010.11.001.

45. Zhang Y, Chen Y, Xia S. Retrospective analysis on the treatment of 231 cases of very low or extremely low birth weight infants. Med J Wuhan Univ. 2016;37(6):990994.

46. Rayner J, McLachlan HL, Forster DA, Peters L, Yelland J. A statewide review of postnatal care in private hospitals in Victoria, Australia. BMC Pregnancy \& Childbirth. 2010;10:26. doi:10.1186/1471-2393-10-26

47. Kurth E, Spichiger E, Zemp Stutz E, Biedermann J, Hösli I, Kennedy HP. Crying babies, tired mothers challenges of the postnatal hospital stay: An interpretive phenomenological study. BMC Pregnancy Childbirth. 2010;10. doi:10.1186/1471-2393-10-21

48. Ya-Ling Lai, Chich-Hsiu Hung, Stocker J, Te-Fu Chan, Liu Y. Postpartum fatigue, baby-care activities, and maternalinfant attachment of vaginal and cesarean births following rooming-in. Appl Nurs Res. 2015;28(2):116120. doi:10.1016/j.apnr.2014.08.002

49. THL. Perinataalitilasto - synnyttäjät, synnytykset ja vastasyntyneet 2013. (National Institute for Health and Welfare, perinatal statistics - parturients, deliveries and newborns). http://www.julkari.fi/bitstream/ handle/10024/116818/Tr23_14.pdf? sequence=3. Updated 2014. Accessed April 2018.

50. Hannula L. Imetysnäkemykset ja imetyksen toteutuminen: Suomalaisten synnyttäjien seurantatutkimus. Perceptions of Breastfeeding and the Outcomes of 
Breastfeeding - A Follow-up Study of Finnish Mothers. Doctoral Dissertation. (in Finnish with English abstract) Annales Universitatis Turkuensis. University Press, Helsinki. Series 2003 C 195.

51. Hannula L, Rytkönen L, Kumpula M, Puukka P, Helenius L, Pakola M. Lisämaidon anto vastasyntyneelle lapsivuodeosastolla. (Giving supplementary milk to the infant in the postnatal ward. (In Finnish with English abstract) Tutkiva hoitotyö. Evidenced Based Nursing. 2008;6(1):12-18.

52. The Finnish Ministry of Justice. Medical research act 488/1999. http://www.finlex.fi/en/laki/ kaannokset/1999/199904881999. Accessed April 2018.

53. Polit DF, Beck CT, eds. Nursing research, generating and assessing evidence for nursing practice. China: Lippincott Williams \& Wilkins; 2012.

54. IBM. IBM corp. released 2013. IBM SPSS statistics for windows, version 22.0. Armonk, NY: IBM corp. . 2013.

55. Elo S, Kyngäs $H$. The qualitative content analysis process. J Adv Nurs. 2008;62(1):107-115. doi:10.1111/j.1365-2648.2007.04569.x

56. Kyngäs $H$, Elo S, Pölkki T, Kääriäinen M, Kanste $O$. Sisällönanalyysi suomalaisessa hoitotieteellisessä tutkimuksessa. Hoitotiede. 2011;23(2):138-148.

57. Elo S, Maria Kääriäinen, Kanste O, Tarja Pölkki, Utriainen K, Helvi Kyngäs. Qualitative content analysis: A focus on trustworthiness. SAGE Open. 2014;4(1):2158244014522633. doi:10.1177/2158244014522633

58. DiGirolamo AM, Grummer-Strawn LM, Fein SB. Effect of maternity-care practices on breastfeeding. Pediatrics. 2008;122:S43-9. doi:10.1542/peds.2008-1315e

59. WHO. Baby-Friendly Hospital Initiative. http://www.who.int/nutrition/publications/ infantfeeding/9789241594950/en/index.html2009]. Updated 2009. Accessed April 2018.

60. Floyd AMD. Neonatal care. challenging designs of neonatal intensive care units. Crit Care Nurse. 2005;25(5):59-66. 